\title{
THE RISKS OF INJURY IN PUBLIC ICE SKATING
}

\author{
P. J. RADFORD, D. M. WILLIAMSON and I. M. R. LOWDON \\ The Accident Service, The John Radcliffe Hospital, Headington, Oxford
}

\section{ABSTRACT}

A prospective survey has been made of the injuries to members of the public attending a well established ice rink in a major city. Comparison is made with series in the literature reporting high levels of injuries, with corresponding demands on local hospital services, from newly established ice rinks. The main conclusion is that demands on hospital services have been markedly reduced for the well established rink, with corresponding savings in health service resources.

Key words: Ice skating injuries

\section{INTRODUCTION}

Ice skating by the public has become more popular in recent years, with the opening of new rinks in several areas of the country. There have been three previous reports in the literature of the injuries encountered in public ice skating in this country (Prescott, 1986; Williamson and Lowdon, 1986; Freeland, 1988). These studies were performed soon after the opening of new rinks in areas which had previously been without one, and in all cases large numbers of extra patients were seen at the local hospital Accident Department as a result. In one study $2.1 \%$ (Prescott, 1986), in another 4\% (Williamson and Lowdon, 1986) and in the third 3\% (Freeland, 1988) of all Accident Department patients during the study period were from the new ice rink.

The currently reported prospective study was performed to document the injuries sustained during public ice skating at Oxford Ice Rink, which has now been in operation for over three years. It was felt that these figures would be more representative of the ongoing injury levels and hence more useful for planning of health service resources.

\section{METHODS}

For two months records were completed for all patients attending the Accident Service at the John Radcliffe Hospital, Oxford, who had been injured at the Oxford Ice Rink. The patients completed a questionnaire detailing their age, sex, nature and circumstances of injury, previous skating experience and level of tuition, if any. The Casualty Officer, seeing the patient, completed a further section on the form giving details of the nature of injuries, primary treatment and follow-up arranged.

Detailed records are maintained at the Oxford Ice Rink of all injuries reported to, and treated by, the on-site First Aid team. These records were inspected for the study period and information recorded in terms of age and sex of patients, nature and circumstances of injury, primary treatment and follow-up arranged.

The study was performed during the same two months of the year as had been a previous study performed immediately after the opening (Williamson and Lowdon, 1986), to allow for seasonal variation in attendances.
Address for correspondence:

Mr. P. J. Radford

Surgical Registrar

Addenbrooke's Hospital

Hills Road

Cambridge CB1 200

\section{RESULTS}

\section{Hospital analysis}

During the study period there were 8,361 attendances at the hospital Accident Service, 80 patients had been injured at the ice rink, representing just under $1 \%$ of the workload. Twenty-three of the injured skaters had definite fractures, two had suspected but not confirmed fractures, two had dislocations and one a tendon laceration. A diagnosis of bruising alone was made in 21 cases, sprain in 14, and simple laceration in 16. Fifty-five out of 80 patients had radiographs performed on the initial visit. Only two patients required hospital admission, but 65 Fracture Clinic appointments ensued as a result of the initial visits. As primary treatment, three patients required fracture manipulation under anaesthesia, two needed dislocations reducing under sedation, 26 needed plaster of Paris immobilisation and 12 patients needed formal suture of lacerations.

The distribution of soft tissue injuries is shown in Fig. 1. The distribution of serious injuries (defined here as those requiring hospital follow-up) is shown in Fig. 2.

Seventy-one per cent had fallen and been injured without the involvement of any other skater, $11 \%$ had fallen as a result of a collision and $18 \%$ had been injured by being

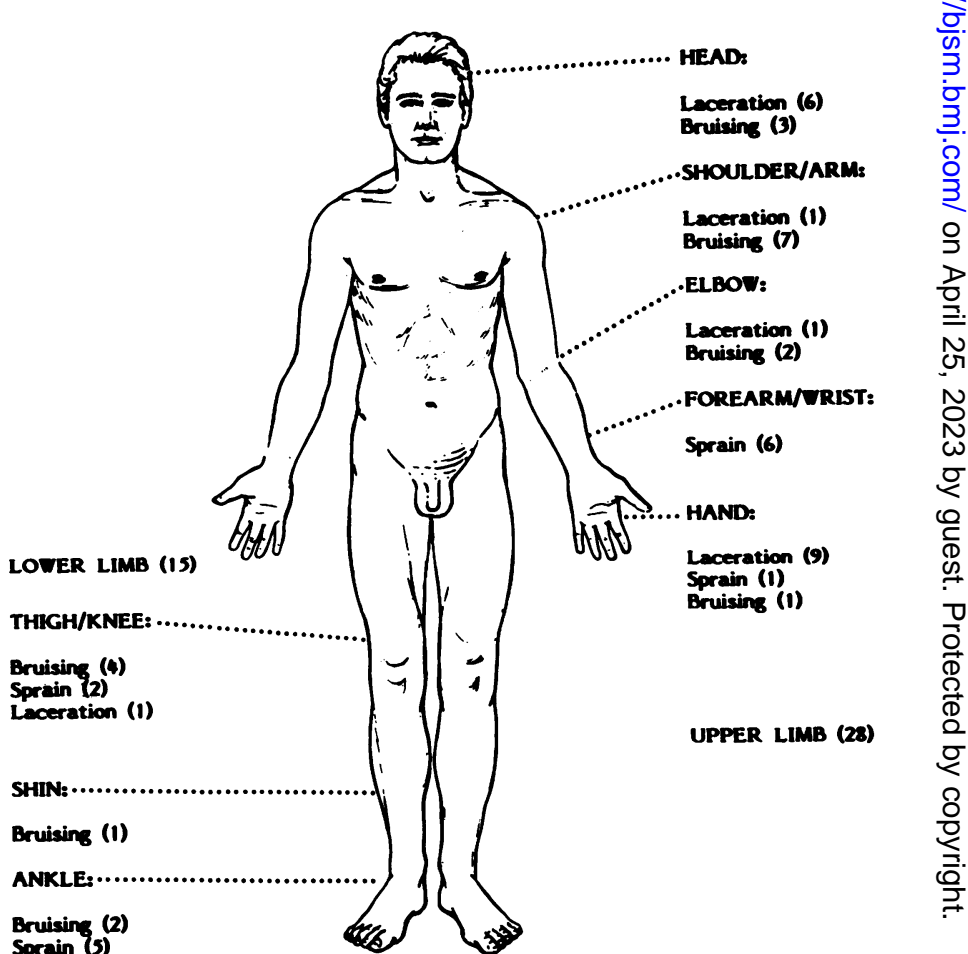

Fig. 1: Pictorial representation of the distribution of minor soft tissue injuries. 


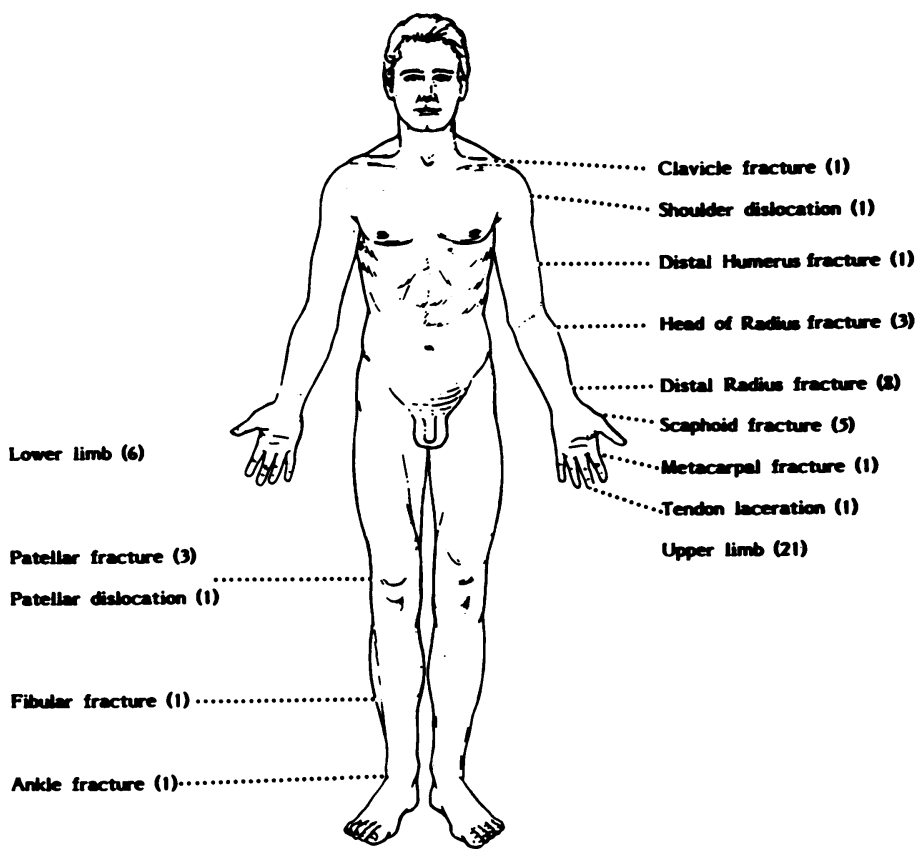

Fig. 2: Pictorial representation of the distribution of significant injuries.

hit by another skater after falling. Fifty-six per cent of the injured skaters were beginners, as defined as having been skating less than 10 times before, $25 \%$ were intermediate in experience and $19 \%$ were experienced skaters. The serious injury rate was higher for the beginners $(51 \%)$ than for the other two groups (29\%).

Eighty-two and a half per cent of the patients were in the 11 to 25 years age group, the overall age grouping being illustrated in Fig. 3. The serious injury rate was lower in this age group however at $34 \%$ compared with $73 \%$ of patients over 25 years attending hospital.

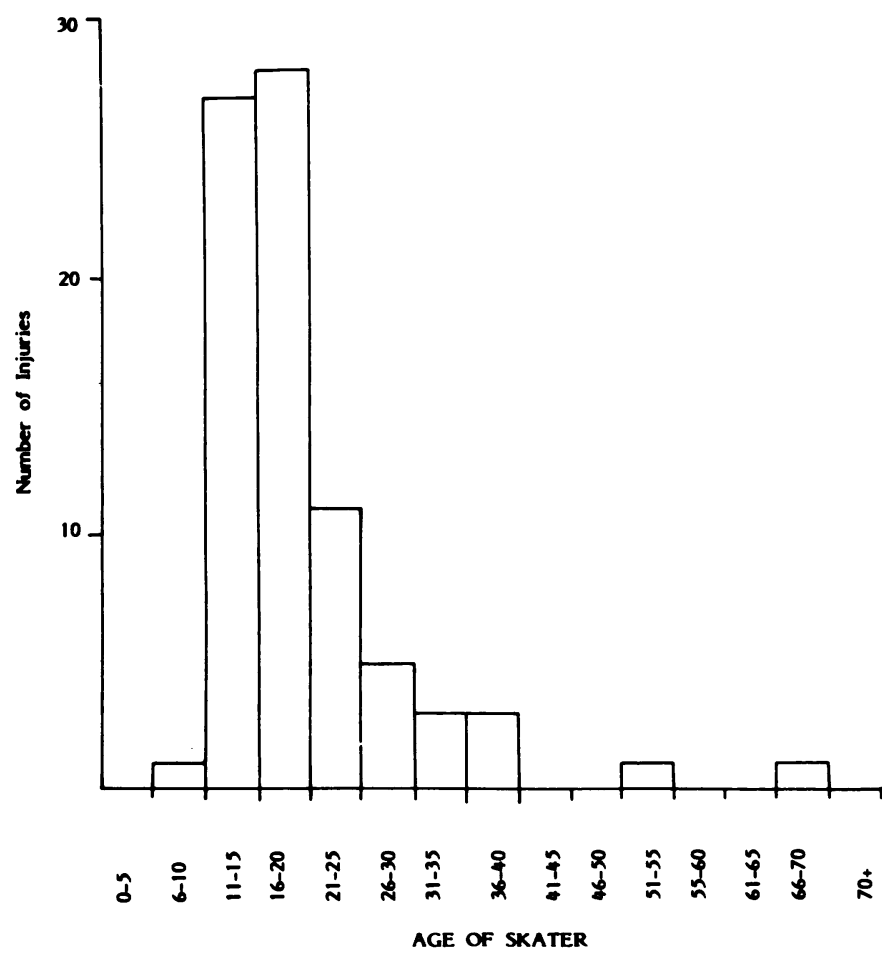

Fig. 3: Histogram showing the ages of the injured in five-year groups.

\section{Ice rink analysis}

There were 82,193 attendances at the ice rink during the study period. Of these, 230 skaters consulted the First Aid team at the rink. $141(61 \%)$ patients were dealt with by the first-aiders alone, $78(34 \%)$ were referred to the study hospital, although 23 declined to attend, and 10 attended hospitals in other areas. The First Aid team dealt with 66 simple lacerations, 45 being on the hand, with 57 cases of simple bruising, 32 simple sprains and an assortment of other minor complaints.

When comparison was made between the hospital and rink records, we found that of the patients seen at the hospital $70 \%$ had been sent from the rink, and $30 \%$ had attended without consulting the first-aiders. There were 24 serious injuries in the former $(43 \%)$ and nine $(37.5 \%)$ in the latter groups. No cases were encountered of patients attending hospital with serious injuries after having been sent home by the First Aid team at the rink.

The overall risk of sustaining an injury requiring attention during this period was $0.31 \%$, the risk of an injury being followed by a hospital attendance was $0.11 \%$ and that of sustaining a serious injury needing further hospital follow-up was $0.03 \%$. Less than $1 \%$ of the total Accident Service attendances were by patients from the ice rink during the study period.

\section{CONCLUSIONS}

The results presented show that the majority of injuries sustained during public ice skating are relatively minor in nature, although there are moderate numbers of skaters reporting them at the rate of $0.31 \%$ of all attendances. Reassuringly the number of serious injuries was low at only $0.03 \%$ of all skating attendances, although these did occupy just under $1 \%$ of the total Accident Department workload.

The analysis reveals that serious injuries tended to result from a fall, usually without any form of collision with another skater, onto the upper limb. It is difficult to suggest any simple ways in which this method of injury can be prevented. A number of the minor injuries were lacerations to the extremities which could have been prevented by protective gloves, and adequately padded clothing.

Comparison with the previously reported studies, including one from the same rink, performed immediately after the opening of new rinks reveals encouraging trends in the injury rates. As the Oxford rink has become established, the number of attendances at the rink has actually increased from 74,676 in the initial study to 82,193 in the currently reported study. The total numbers of reported injuries has declined from $0.38 \%$ to $0.31 \%$ of attendances at the rink. More impressively, the rate of serious injuries has declined from $0.14 \%$ to $0.03 \%$ of all attendances. Ice skaters now occupy just less than $1 \%$ of Accident Service attendances compared with $4 \%$ initially.

There is no evidence that the injured skaters are significantly more experienced in the currently reported series than those in the previous series. We therefore conclude that increased safety measures at the rink (Oxford City Council - personal communication) have led to the much reduced rate of serious injuries, and that the increased experience of the staff at the rink has led to greater treatment by first-aiders alone of trivial injuries, with corresponding savings in hospital resources.

Thus we have shown that the implications for health service resources of public ice skating are much less than 
was at first feared, after the reports of previous authors. We would encourage ice rinks to develop a properly trained First Aid team as this produces definite savings in hospital Accident Department time.

\section{ACKNOWLEDGEMENTS}

We wish to thank Oxford City Council and the staff of the Oxford Ice Rink for their considerable help, the Consultants at the Accident Service, John Radcliffe Hospital, Oxford for allowing us to report upon their patients; and the
Department of Medical Illustration, Addenbrooke's Hospital, Cambridge, for preparing the illustrations.

\footnotetext{
References

Freeland, P., 1988 "Implications of two newly opened ice rinks on an accident and emergency department". British Medical Journal 296: 96

Prescott, M. V., 1986 "The effect of opening an ice-rink on the accident and emergency department of a district general hospital". Archives of Emergency Medicine 3: 107-110.

Williamson, D. M. and Lowdon, I. M. R., 1986 "Ice Skating Injuries". Injury 17: 205-207.
}

\section{BOOK REVIEW}

Title: EXERCISE: BENEFITS, LIMITS AND ADAPTATIONS

Editors: $\quad$ D. Macleod, R. Maughan, M. Nimmo, T. Reilly and C. Williams

Publishers: $\quad$ E. and F. N. Spon, London

Price: $€ 12.50 \quad 396$ pages Figs. Index ISBN 0419141405

This book is a collection of papers presented at a symposium organised by the Edinburgh Post-graduate Board of Medicine called "Exercise: benefits, limits and adaptations". The organising committee, contributors and participants brought together many of the household names in sports medicine, among them Astrand, Morris and Saltin. This broad experience and expertise produced papers which also ranged in their content and emphasis, from the general review of epidemiological studies of the benefits of exercise, to the specifics of exercise.

The book is in five parts, Exercise and medicine, Short-term activity, Endurance: a multi-disciplinary perspective, Women and sport, and Environmental factors. Each paper was concluded by a question and answer section which further highlighted their content. All sections are then drawn together in the concluding address by P.-O. Astrand who summarises the proceedings by stating that although evidence to support the view that exercise prevents disease is inconclusive; "there is a total, even unanimous agreement, shared by all exercise physiologists, that regular exercise is essential for optimal function of the human body."

It was gratifying to read a book on sports medicine which in my opinion has at last appeared to overcome the singularly British problem of the acceptance of the term sports medicine. This multi-disciplinary approach and the skilful editing by the authors has produced a source of knowledge, information and reference for all those involved in the practice or research of exercise, science and medicine.

W. M. Williamson

\section{BOOK REVIEW}

Title:

\section{BIBLIOGRAPHY ON RUGBY INJURIES}

Authors: $\quad$ Patricia Coleman and Jonathon Nicholl

Publisher: $\quad$ Department of Community Medicine, University of Sheffield 1988

$$
\text { Price: } € 5.00 \quad 48 \text { pages No figs. }
$$

This bibliography of injuries sustained during rugby football has been compiled by the Medical Care Research Unit of the Department of Community Health, University of Sheffield, with financial assistance from the Sports Council, to whom gratitude is expressed. The authors have found 226 references in the literature collected from all rugby-playing countries, but have added another 13 in a supplementary list that includes the March issue of the British Journal of Sports Medicine, so it could not be more up-to-date. There is a two-page introduction, explaining the method used for data collection, and the system of classifying it, first by year of publication, then cross-indexed by key words. A computer search for any particular topic should be easy, but even without computer facilities it should not take long to find reference sources from any special country, any partcular type of injury or anatomical site. The bibliography should prove invaluable to anyone concerned with sports injuries who is hoping to write up work for publication. The first reference quoted is in 1954. Each reference starts with its accession number, followed by the author(s), then the title of the article, the journal and volume, page numbers, etc. The later section, classified by key words, is not easily understood, as the accession numbers are on the extreme left of each page and covered by the sliding binding. The binding has therefore to be removed for the number to be read, and as the pages are not numbered I can see chaotic disarrangement of the lists unless great care is taken. I hope the authors will bear this in mind before printing more copies. I shall be sending my review copy to the BASM's Library Collection at the London Sports Medicine Institute where it can be available to those interested, though at only $£ 5$ it is well worth buying a copy from the Medical Care Research Unit, Department of Community Medicine, University of Sheffield Medical School, Beech Hill Road, SHEFFIELD S10 2RX (cash with order). 